\title{
Simplified Method for the Seismic Design of Low-Rise, Shear Wall Base- Isolated Buildings
}

\author{
Arturo Tena-Colunga*
}

Departamento de Materiales, Universidad Autónoma Metropolitana Azcapotzalco, Av. San Pablo \# 180, 02200 México, D.F., Mexico

\begin{abstract}
A simplified method for the seismic design of low-rise, base-isolated shear wall structures is proposed in MOC-2012. This simplified method is basically a hybrid method, where the design of the isolation system is a simpler version for the static method available in US guidelines for the design of base-isolated structures and the design of the superstructure essentially is an improved version of the simplified method for the seismic design of conventional low-rise shear wall structures of Mexican seismic codes. The application of this method and its effectiveness to obtain safe designs is illustrated with a practical example. It is anticipated this simple methodology would help promote the use of base isolation in low-rise shear wall structures and reduce their vulnerability when subjected to strong earthquakes.
\end{abstract}

Keywords: Base isolated structures, design guidelines, low-rise shear wall structures, seismic codes, simplified method for seismic design.

\section{INTRODUCTION}

The Manual of Civil Structures (MOC), one of the model design codes in Mexico, was updated. This manual is frequently used in the entire nation in lieu of a specific code for a state or a city. The new version for this manual and all the chapters was published in $2008[1,2]$. The bases and design philosophy of previous and current seismic design provisions of MOC code in English language can be found [2,3].

There is one new chapter in MOC-2012 devoted to the seismic design of base-isolated structures [4], the philosophy of which is presented in detail in [5]. Among the innovations of these base-isolation guidelines is that a simplified method of seismic analysis is allowed for the design of low-rise, shear-wall base-isolated structures.

This method is hybrid in nature, as briefly mentioned before. The design of the isolation system is a simpler but more restrictive version for the static method for base-isolated structures, which is very similar to US guidelines [6-9]. The design of the superstructure essentially is the improved simplified method for the design of conventional structures but the effective shear area factors $\left(F_{A E}\right)$ that are defined for the walls are those for elastic response $[1-5,10]$. The effects of the vertical component of the ground motions are neglected in the design process when using the simplified method.

The purpose of allowing such method for design purposes is to favor the application of base-isolation in regular and squatty shear wall structures by reducing its complexity. It makes no sense to complicate the design of base-isolated structures when the superstructure is simple, regular, squatty and very rigid, as their seismic response is relatively easy to

*Address correspondence to this author at the Departamento de Materiales, Universidad Autónoma Metropolitana Azcapotzalco, Av. San Pablo \# 180, 02200 México, D.F., Mexico; Tel: +52-55 5318-9460;

Fax: +52-55 5318-9085; E-mail: atc@correo.azc.uam.mx assess. This is the concept behind the simplified method of analysis for base-isolated structures in MOC-2012.

The requirements to apply this simplified method and the method itself are described in following sections. A design example is also provided to illustrate the application of the method and its effectiveness to lead to safe structural designs.

\section{SIMPLIFIED METHOD}

\section{Requirements for Application}

The base-isolation system and the structure above the isolation system can be designed using the simplified method of seismic analysis (SMSA) only if the building satisfies all the following requirements:

A. The base-isolated structure complies with the following twelve conditions of structural regularity:

1. The distribution in plan of story mass, shear walls and other lateral resisting elements must be approximately symmetrical with respect to two principal axes of the building.

2. The ratio of the height of the building to the smallest plan dimension shall not exceed $1.5\left(H / L_{2} \leq 1.5\right)$.

3 . The ratio of the largest to the smallest plan dimensions shall not exceed $2.0\left(L_{1} / L_{2} \leq 2.0\right)$.

4. Plan configurations of structures shall not contain reentrant corners or offsets exceeding 20 percent of the plan dimension of the structure in the given direction.

5. Each story has a rigid floor system with sufficient strength capacity.

6. There are no diaphragm discontinuities or variations in stiffness, including those having cutout or open ar- 
eas greater than 20 percent of the gross enclosed area of the diaphragm or 20 percent greater than the plan dimension of the structure in the parallel direction. In addition, the open areas shall not vary in position between adjacent stories or shall not introduce important asymmetries in plan.

7. The weight of any story, including the seismic accidental live loading, shall not be greater than 110 percent or less than 70 percent the weight of the adjacent story below the one in consideration $\left(0.7 \leq W_{i} / W_{i-1} \leq\right.$ 1.1). A roof which is lighter than the floor below need not to be considered.

8. The plan area of any story shall not be greater than 110 percent or less than 70 percent the area of the adjacent story below the one in consideration $\left(0.7 \leq A_{i} /\right.$ $\left.A_{i-1} \leq 1.1\right)$. The roof is exempt of this consideration. In addition, the plan area of any story shall not exceed in more than $50 \%$ the minimum area of the lower stories $\left(A_{i} / A_{\min } \leq 1.5\right)$.

9. All columns are laterally restrained in their main orthogonal directions at all stories by rigid diaphragms, floor slabs or beams.

10. The lateral shear stiffness or strength of any story shall not exceed more than 50 percent the shear stiffness or strength of the adjacent story below the one in consideration $\left(K_{i} / K_{i-1} \leq 1.5\right)$. The top story is exempt from this requirement.

11. The torsional plan eccentricities $\left(e_{s i}\right)$, computed for any story from static seismic analysis, shall not exceed 5 percent of the plan dimension in the given direction of analysis $\left(e_{s i} \leq 0.05 B_{i}\right)$.

12. The torsional plan eccentricity for the isolation system $\left(e_{s a}\right)$, shall not exceed 2 percent of the plan dimension in the given direction of analysis $\left(e_{s a} \leq\right.$ $0.02 B_{a}$ ).

B. The structure above the isolation system is composed of shear walls and satisfies also the following additional requirements of the SMSA of conventional shear wall buildings:

1. The walls must carry more than $75 \%$ of the gravitational loads.

2. The structure shall not be taller than four stories in height or 13 meters, whichever is smaller.

C. The base-isolated structure is located at least $50 \mathrm{~km}$ away from any known active fault.

D. The base-isolated structure is located on firm soils or rock [the site factor ranges from 1.0 to 1.25 $\left(1.0 \leq F_{s} \leq 1.25\right)$ or the shear wave velocity is $\left.v_{s} \geq 250 \mathrm{~m} / \mathrm{s}\right]$.

E. The effective period of the base-isolated structure at the design displacement, $T_{a s}$, is greater or equal to $1.5 \mathrm{sec}-$ onds but less or equal to 3.0 seconds, this is, $1.5 s \leq T_{a s} \leq 3 s$.

F. The effective period of the base-isolated structure at the design displacement, $T_{a s}$, is greater than five times the elastic, fixed-base period of the structure above the isolation system, $T_{E}$, this is, $T_{a s} \geq 5 T_{E}$.
G. The isolation system meets the following criteria:

1. The effective stiffness of the isolation system at the design displacement is greater than one-third of the effective stiffness at 20 percent of the design displacement (Fig. 1).

2. The isolation system is capable of producing a restoring force as specified in required prototype testing section of the guidelines.

3. The isolation system has force-deflection properties that are independent of the rate of loading.

4. The isolation system has force-deflection properties that are independent of vertical load and bilateral load.

It is worth noting that requirements $\mathrm{A} 2$ and $\mathrm{A} 3$, which are more strict than those requested for most conventional structural systems, are specified by the SMSA for low-rise structures [i.e., 10].

Requirement A11 for base-isolated structures $\left(e_{s i} \leq\right.$ $\left.0.05 B_{i}\right)$ is more strict compared to conventional structures and the SMSA $\left(e_{s i} \leq 0.1 B_{i}\right)$, as for elastic response, a smaller static eccentricity should be allowed in the simplified method, according to the results of a parametric study [11]. Requirement B2 is a little more restrictive as well, as for conventional structures, the SMSA is allowed for structures up to five stories in height [10].

Finally, requirements $\mathrm{A} 12, \mathrm{C}$ and $\mathrm{F}$ are more strict with respect to what it is allowed in the static method for baseisolated structures [i.e., 4, 5]. Requirement A12 is set to limit one source that amplifies considerably the torsional response in base-isolated structures: eccentricities in the isolation system [i.e., 12-15]. Requirement $\mathrm{C}$ is specified in order that the effects of the vertical component of the ground motions could be neglected in the design process when using the simplified method. However, it is worth noting that the effects of the vertical components cannot be neglected for near-fault ground motions since the isolators can undergo tensile loads, especially when the vertical component of the ground motion has a relatively high peak value [16]. Requirement $\mathrm{F}$ is set to warrant a reasonable uncoupled dynamic response, controlled essentially by the isolation system.

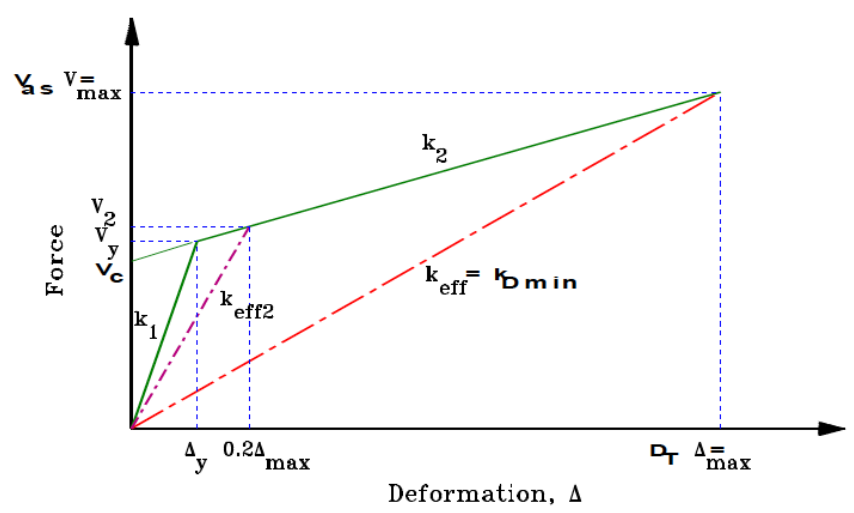

Fig. (1). Design envelope curve for bilinear isolators that follow criterion G1. 


\section{General Design Guidelines}

As noted earlier, the simplified method is a simpler version of the static method allowed in MOC-2012 $[4,5]$ and, for the design of the isolation system, it is similar to the static procedure outlined in design guidelines for baseisolated structures of the United States [i.e., 6-9], with adaptations to the seismic design philosophy of current MOC code and original proposals from research studies conducted in Mexico and worldwide. The design of the superstructure is based upon the updated version of the SMSA of Mexican codes for low-rise, squatty shear-wall structures, where elastic response is expected [10].

Therefore, the natural period for the base-isolated structure, $T_{a s}$, is estimated as:

$$
T_{a s}=2 \pi \sqrt{\frac{W}{g k_{D \min }}}
$$

where $W$ is the weight of the structure above the isolation system and $k_{D \min }$ is the effective lateral stiffness of the isolation system at the total design displacement, $D_{T}$.

The design displacement of the center of rigidity of the isolation system in the direction of analysis for the Maximum Credible Earthquake (MCE), $D_{D}$, is computed as:

$$
D_{D}=F_{c} S_{d}\left(T_{a s}\right)
$$

where $F_{c}=1.1$ is the load factor for combinations of lateral and gravitational loads according to MOC.

This design displacement has to be amplified to account for orthogonal effects in the horizontal plane $\left(D_{2 D}\right)$ as follows, based on the extensive parametric study summarized in [17]:

$$
D_{2 D}=D_{D}\left(1.3-0.02 T_{a s}\right) ; \quad T_{a s} \geq 1.5 s
$$

The amplification of the total design displacement $\left(D_{T}\right)$ to account for torsional effects due to actual and accidental eccentricities is crudely estimated for design purposes as:

$$
D_{T}=1.1 D_{2 D}
$$

The increment of $10 \%$ for the design displacement due to torsional response is based upon the study presented by Seguín [18]. In the cited study, it is shown that for elastomeric base-isolated structures, amplifications in the bearing displacement due to accidental eccentricities of five percent the longest plan dimension of the structure perpendicular to the direction of force under consideration do not exceed $10 \%$, considering an ample range of the rotational to translational frequency ratio of the isolation system $\left(\Omega_{0 a s}\right)$.

The minimum design shear force for the isolation system, the foundation and structural elements below the isolation system, $V_{a s}$, is computed as:

$$
V_{a s}=k_{D \min } D_{T}
$$

where $k_{D \min }$ is the effective stiffness of the isolation system at the design displacement in the horizontal direction under consideration (Fig. 1).

The equation to define $V_{E}$, the minimum design shear force for the structure above the isolation system is:

$$
V_{E}=\frac{V_{a s}}{Q_{a s}^{\prime}}
$$

where $Q_{a s}^{\prime}$ is the seismic reduction factor for baseisolated structures that is estimated as outlined in [5]. The value of $V_{E}$ shall not be taken as less than the following:

1. The lateral seismic force required for a fixed-base structure of the same effective weight, $W$, and a period equal to the isolated period, $T_{a s}$.

2. The base shear corresponding to the factored design wind load.

It is worth noting that the limits in $V_{E}$ mostly coincide with current proposal of ASCE-7 [7] as per section 17.5.4.3, but item 3 ("the lateral seismic force required to fully activate the isolation system multiplied by 1.5 ") is not included in MOC-2012 [4].

The vertical distribution of lateral forces in the superstructure is given by the following expression:

$$
F_{i}=V_{E} \frac{W_{i}}{\sum W_{i}}
$$

where $F_{\mathrm{i}}$, and $W_{i}$ are respectively the lateral force and the weight above the isolation system of level $i$. and the remaining terms have been already defined. As observed, in the simplified method of MOC-2012 a uniform lateral load distribution is allowed, as it is required that base-isolated structures should be reasonably uncoupled $\left(T_{a s} / T_{E} \geq 5\right)$.

Finally, using the SMSA, it is allowed to design the structure above the isolation system by just computing the seismic shear forces that each wall has to carry according to its relative shear stiffness and then assessing the strength required by the walls to carry the attracted shear forces.

As the SMSA is based on an idealized distribution of lateral forces of symmetric shear-wall structures with rigid diaphragms [10], the shear force attracted by any wall $j$ at level $i, V_{j i}$, is computed from the shear force acting at level $i, V_{i}$, as follows:

$$
V_{j i}=V_{i} \frac{F_{A E_{i j}} A_{T_{j i}}}{\sum F_{A E_{j i}} A_{T_{j i}}}
$$

where $F_{A E_{j i}}$ is the effective shear area factor of wall $j$ at level $i$ (proposed by SMSA) and $A_{T_{i j}}$ is the cross section area (axial area) of wall $j$ at level $i$.

For base-isolated structures, elastic response for the superstructure is desirable, so the effective shear area factors, $F_{A E}$ for this condition are:

$$
F_{A E}=\left\{\begin{array}{cl}
1.5+\frac{h^{\prime}}{L}-1.5\left(\frac{h^{\prime}}{L}\right)^{2} & \text { if } \quad \frac{h^{\prime}}{L} \leq 1 \\
2.2-1.5 \frac{h^{\prime}}{L}+0.3\left(\frac{h^{\prime}}{L}\right)^{2} & \text { if } 1 \leq \frac{h^{\prime}}{L} \leq 2.5
\end{array}\right.
$$

where $h^{\prime}$ and $L$ are respectively the height and the length of the wall under consideration.

Once all walls are correctly designed by shear forces, the design procedure using the SMSA is over, as no further reviews are needed, for example, assessing torsional effects, overturning moments, P- $\Delta$ effects, or limit states such as if lateral drifts meet code requirements, etc. Therefore, the 
SMSA is very attractive as it allows studying quickly different options for the design of low-rise buildings with a small computational effort, thus a modest computer with a spreadsheet program becomes a powerful tool to implement the SMSA.

\section{DESIGN EXAMPLE}

The application of the simplified method is illustrated with the design of the four-story, $10.8 \mathrm{~m}$ in height confined masonry shear wall building the plan of which is shown in (Fig. 2).

The typical story height for the building is $2.7 \mathrm{~m}$. Confined masonry walls are built with fired clay bricks with thickness $t=12.5 \mathrm{~cm}$ and will be jointed with mortar type I according to Mexican masonry guidelines [i.e., 19]; this mortar is similar to mortar types $\mathrm{M}$ or S specified in US masonry codes. The confining RC elements shall be designed to fulfill the requirements specified in Mexican masonry guidelines. Dead loads due to the RC floor system and finishings are $\omega_{\mathrm{D}}=500 \mathrm{~kg} / \mathrm{m}^{2}$ at the roof level and $\omega_{\mathrm{D}}=450 \mathrm{~kg} / \mathrm{m}^{2}$ at the remaining stories. According to $\mathrm{MOC}$, live loads for vertical load combinations are $\omega_{\mathrm{L}}=100 \mathrm{~kg} / \mathrm{m}^{2}$ and $\omega_{\mathrm{L}}=250 \mathrm{~kg} / \mathrm{m}^{2}$ for the roof and intermediate levels respectively, and for combinations with lateral loads are respectively $\omega_{\mathrm{L}}=70 \mathrm{~kg} / \mathrm{m}^{2}$ and $\omega_{\mathrm{L}}=180 \mathrm{~kg} / \mathrm{m}^{2}$. The volumetric weight for the mancraft fired clay brick is $\gamma=1.3$ ton $/ \mathrm{m}^{3}$ and no finishings will be placed on the walls as the architectural design will take advantage of their aesthetics in both exterior and interior.

The building is located at a distance of $80 \mathrm{~km}$ away from the nearest active fault. The characteristics of the soil type profile for the site are available from a detailed geotechnical study and, according to MOC-2008 guidelines [1,2], the characteristics are: peak acceleration in the bedrock $a_{0}^{r}=0.157 \mathrm{~g}$, fundamental site period $T_{s}=0.5 \mathrm{~s}$ and site factor $F_{s}=1$, so their corresponding acceleration design spectra is shown in (Fig. 3a) and the control periods $T_{a}$ and $T_{b}$ that define the plateau are $T_{a}=0.175 \mathrm{~s}$ and $T_{b}=0.6 \mathrm{~s}$.
It is required to perform a preliminary design for a baseisolation project with lead-rubber bearings (LRB) using the simplified method.

\section{Review of Requirements for Application}

The first step is to ensure that all requirements to use the simplified method are satisfied. Regarding the 12 conditions of structural regularity, from the description of the building, the structural system and the plan shown in (Fig. 2), it can be concluded that conditions A1, A4, A5, A6, A7, A8, A9 and A10 are reasonably satisfied. Condition A2 (slenderness) is also satisfied, as $\mathrm{H} / \mathrm{L}_{2}=10.8 / 9.5=1.14<1.5$. Condition $\mathrm{A} 3$ is also met as $\mathrm{L}_{1} / \mathrm{L}_{2}=18 / 9.5=1.89<2$.

The plan for the structure (Fig. 2) is completely symmetric with respect to the $\mathrm{Y}$ axis; however, there is a small eccentricity offset with respect to the $\mathrm{X}$ axis that has to be evaluated in order to discern if regularity conditions A11 and A12 are satisfied. This evaluation is done using a simplified calculation to estimate the static eccentricity that is allowed when using the simplified method (Eq. 10), as schematically shown in (Fig. 4) and explained in greater detail elsewhere [i.e., 10, 19, 20]:

$$
e_{s j}=\frac{\left|\sum_{i=1}^{n} x_{i} F_{A E i} A_{T i}\right|}{\sum_{i=1}^{n} F_{A E i} A_{T_{i}}} \leq 0.05 B_{j}
$$

From the dimensions of the plan shown in (Fig. 2) and the illustration in (Fig. 4), this review is easily done with the help of Table 1. From the results computed in Table $\mathbf{1}$ it is obtained that:

$$
e_{s y}=\frac{\left|\sum_{i=1}^{n} y_{i} F_{A E i} A_{T i}\right|}{\sum_{i=1}^{n} F_{A E i} A_{T_{i}}}=\frac{0.6173}{6.7163}=0.092 \mathrm{~m} \leq 0.05(9.5)=0.475 \mathrm{~m}
$$

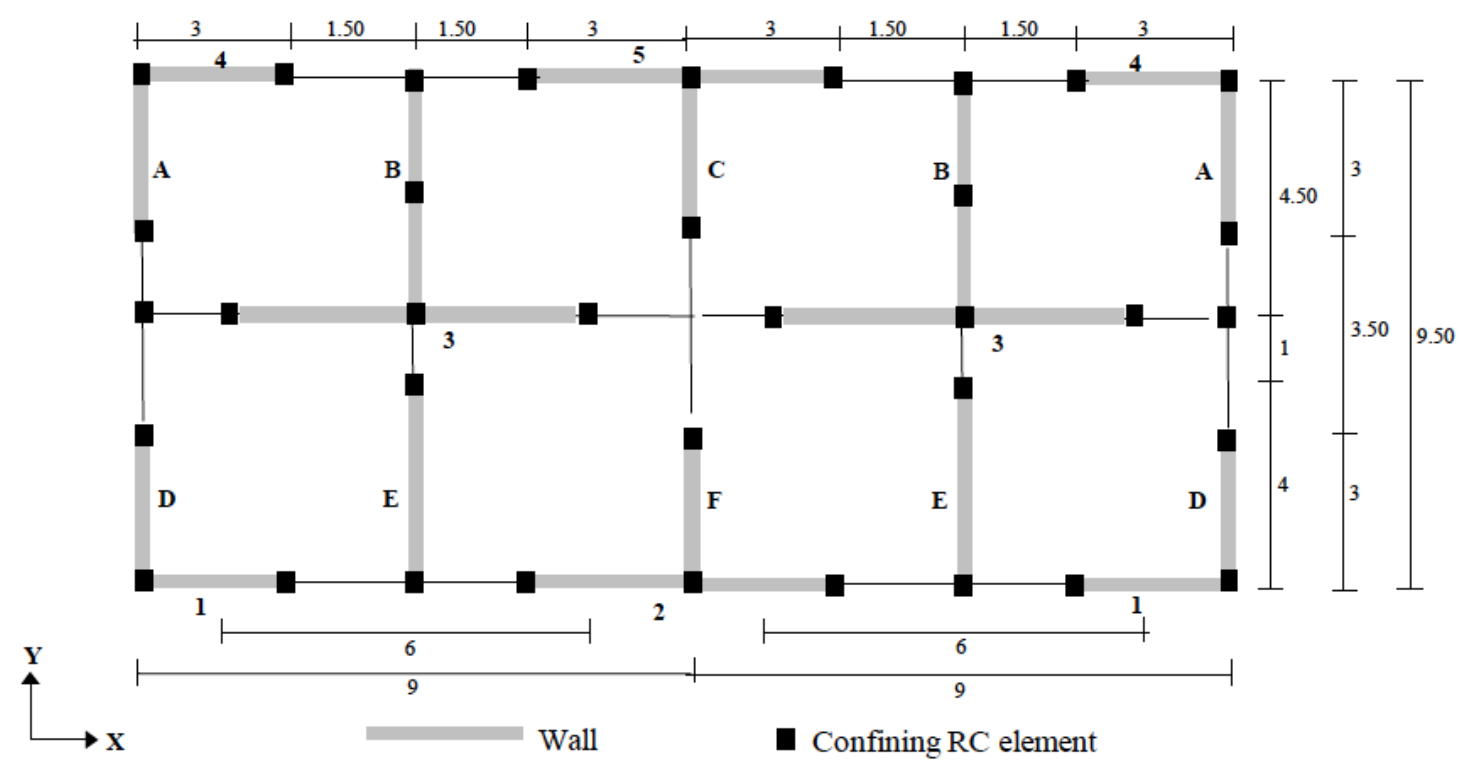

Fig. (2). Plan for a four-story, confined masonry shear wall building (dimensions in meters). 


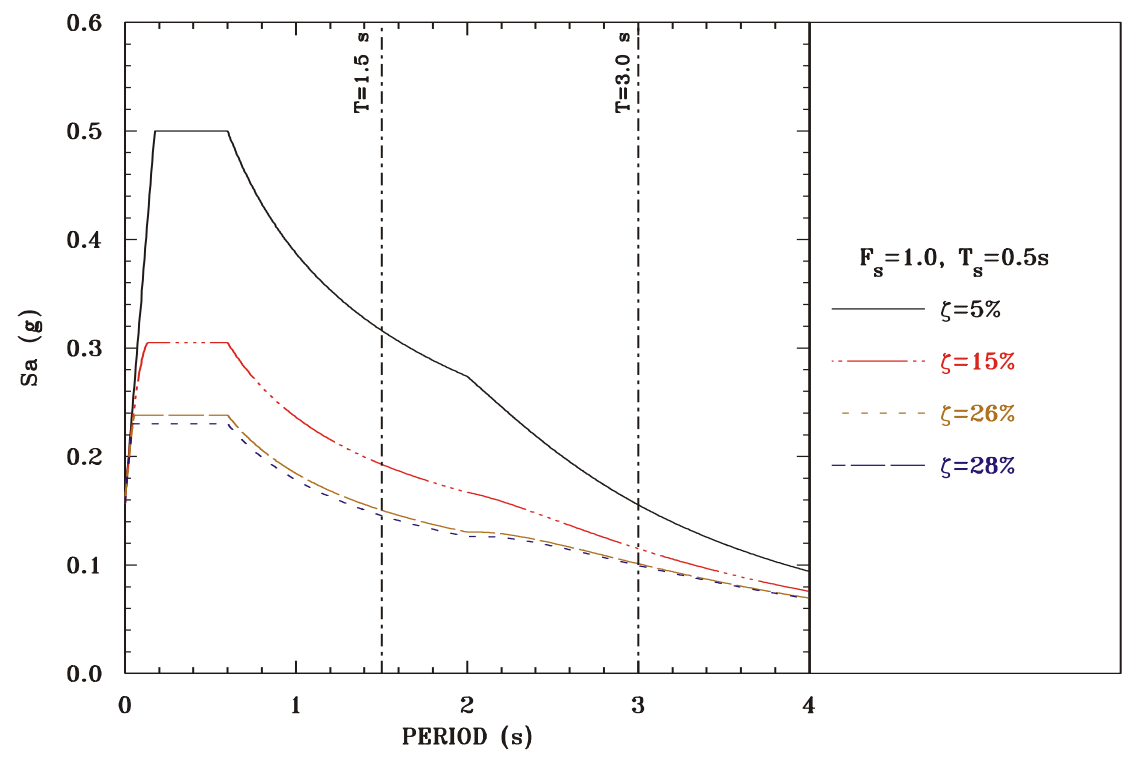

a) Acceleration design spectra

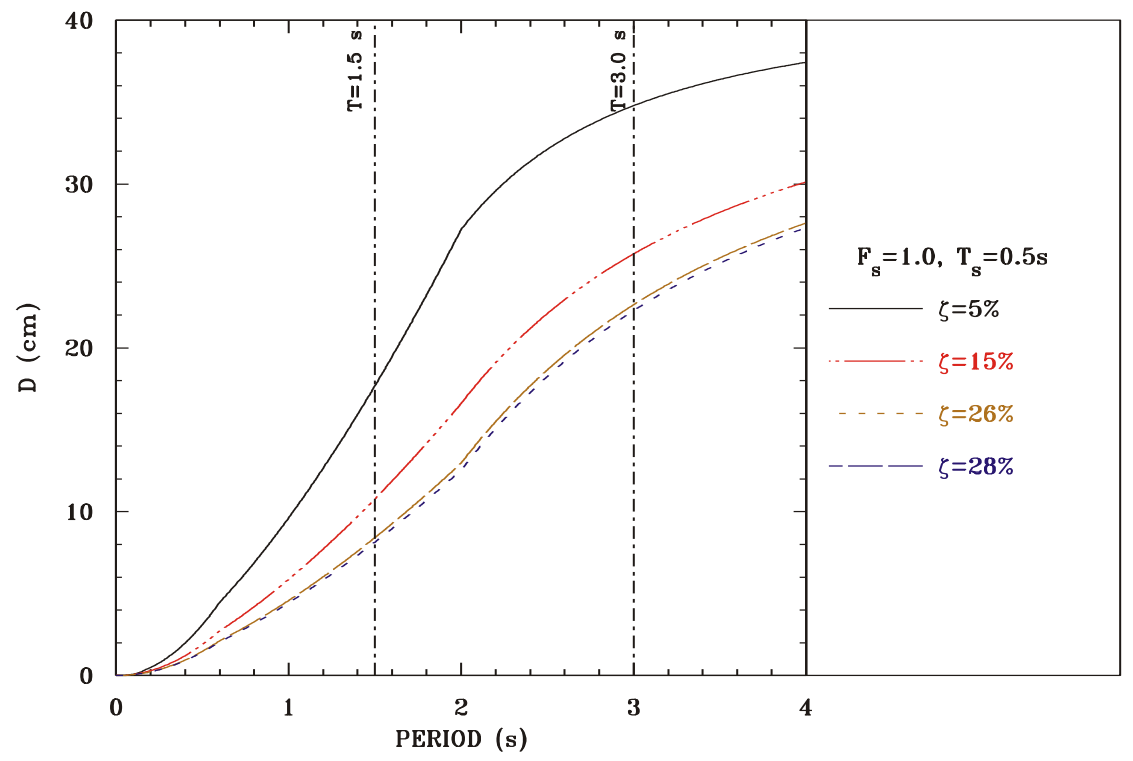

Fig. (3). Design spectra for a site with $a_{0}^{r}=0.157 g, T_{s}=1.5 \mathrm{~s}, P_{s}=0.7832$ and $F_{s}=1$.

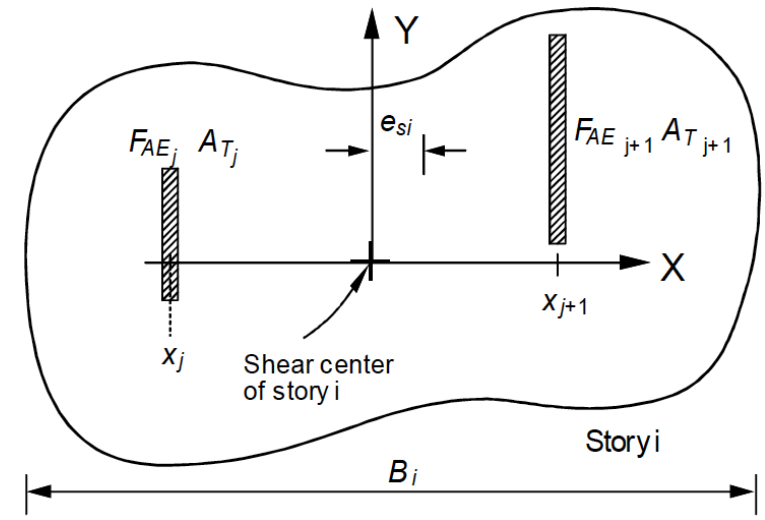

Fig. (4). Definition of static eccentricity for the SMSA of Mexican Codes. therefore, condition A11 is satisfied as $e_{s y} / B=0.092 / 9.5=0.01 \leq 0.05$. As the bearings will be placed as symmetric as possible, condition A12 should also be met, since $e_{s a}$ should be similar to $e_{s y}$, therefore, within allowable limits.

From the definition of the problem and the plan of the building (Fig. 2), it is found that requirement B1 is fulfilled. Requirement B2 is satisfied as the building has four stories and its total height is $10.8 \mathrm{~m}$. From the information that is given in the example, it is concluded that requirements $\mathrm{C}$ and $\mathrm{D}$ are also fulfilled. Finally, requirements $\mathrm{E}, \mathrm{F}$ and $\mathrm{G}$ will be met within the design process. Therefore, it can be concluded that the building structure in (Fig. 2) satisfies the requirements to use the simplified method. 
Table 1. Calculation of the static eccentricity for the SMSA of Mexican Codes.

\begin{tabular}{|c|c|c|c|c|c|c|}
\hline 1 & -4.6875 & 0.375 & 0.90 & 1.185 & 0.4444 & -2.0830 \\
\hline 2 & -4.6875 & 0.75 & 0.45 & 1.6463 & 1.2347 & -5.7876 \\
\hline 3 & 0.25 & 0.75 & 0.45 & 1.6463 & 1.2347 & 0.3087 \\
\hline 4 & 4.6875 & 0.375 & 0.90 & 1.185 & 0.4444 & 2.0830 \\
\hline 4 & 4.6875 & 0.375 & 0.90 & 1.185 & 0.4444 & 2.0830 \\
\hline 5 & 4.6875 & 0.75 & 0.45 & 1.6463 & 1.2347 & 5.7876 \\
\hline$\Sigma$ & & & & & 6.7163 & 0.6173 \\
\hline
\end{tabular}

\section{Estimate of the Seismic Weight and Fixed-Base Periods}

The estimate of the seismic weight is crudely done by computing the own weight of the structural system due to dead and live loads, plus the own weight of walls and the weight of the slab above the isolation system. For simplicity, it will be assumed that the slab above the isolation system weights exactly the same as the slabs in intermediate floors. It can be obtained from (Fig. 2) that the total length of walls at each plan is $L_{m}=71 \mathrm{~m}$ and the linear weight of walls is $\omega_{\mathrm{w}}=1.3(2.7)(0.125)=0.44 \mathrm{Ton} / \mathrm{m}$. Therefore, from the remaining data given in the example the total weight $\mathrm{W}$ can be estimated as:

$$
\begin{aligned}
& W=W_{\text {structure }}+W_{\text {isolation slab }}=W_{\text {stories }}+W_{\text {walls }}+W_{\text {isolation slab }} \\
& W=[0.57+3(0.63)](18)(9.5)+ \\
& 4(71 \mathrm{~m})(0.44 \text { Ton } / \mathrm{m})+0.63(18)(9.5) \\
& W=420.66+124.61+107.73 \rightarrow W=653 \text { Ton }
\end{aligned}
$$

An estimate of the natural period for the fixed-base structure is also necessary. For this purpose, the approximate formula proposed by Murià and González [21] for fixed-base confined masonry buildings is used. Therefore, as the building is four stories in height $(\mathrm{N}=4)$, then:

$$
T_{E} \approx 0.04 N=0.04(4)=0.16 s
$$

\section{Design of the Isolation System}

There are some options already available in the literature for the preliminary design of lead-rubber bearings [i.e., 2224]. In this example, the general procedure outlined in [24] will be adapted and used.

The primary curve for the isolation system should be defined in order to satisfy requirement G1 schematically shown in (Fig. 1); therefore, $k_{D \text { min }}=k_{\text {eff }} \geq \frac{1}{3} k_{\text {eff } 2}$. As the postyielding stiffness ratio $k_{2} / k_{1}$ depends primarily on the characteristics of the isolation system and since $k_{2} / k_{1} \cong 0.1$ for lead-rubber bearings, to satisfy the primary curve for $k_{2} / k_{1}=0.1$, then:

$$
V_{2}=0.6 V_{\max }=0.6 V_{a s}
$$

$$
\begin{aligned}
& V_{a s}=1.8 V_{y} \\
& \Delta_{y}=\frac{D_{T}}{9} \\
& k_{1}=5 \frac{V_{a s}}{D_{T}}=5 k_{e f f} \\
& k_{2}=0.5 k_{\text {eff }}
\end{aligned}
$$

The initial yield force $V_{y}=\kappa W$ for the isolation system should be proposed or estimated as a function of the expected design displacement $D_{T}$ and the equivalent viscous damping at that design displacement $\beta_{D}$, which can be estimated for a bilinear system as:

$$
\begin{aligned}
& \beta_{D}=\frac{1}{2 \pi}\left[\frac{E_{c y c l e}}{k_{D \min }\left(D_{T}\right)^{2}}\right]=\frac{1}{2 \pi}\left[\frac{E_{c y c l e}}{V_{a s} D_{T}}\right] \\
& E_{c y c l e}=4 V_{c}\left(D_{T}-\Delta_{y}\right)=4\left(V_{a s}-k_{2} D_{T}\right)\left(D_{T}-\Delta_{y}\right)
\end{aligned}
$$

where $V_{c}$ is the characteristic shear force (Fig. 1).

If $k_{2} / k_{1}=0.1$, these expressions can be further reduced from Eqs. 11 to 15 as:

$$
\begin{aligned}
& E_{\text {cycle }}=3.6 V_{y}\left(D_{T}-\Delta_{y}\right)=28.8 V_{y} \Delta_{y} \\
& \beta_{D}=\frac{1}{2 \pi}\left[\frac{28.8 V_{y} \Delta_{y}}{1.8 V_{y}\left(9 \Delta_{y}\right)}\right]=0.283
\end{aligned}
$$

Therefore, it is observed that $\beta_{D}$ is constant once the primary curve is defined in terms of $k_{2} / k_{1}$ and $\Delta_{y} / D_{T}$, regardless of the yield force $V_{y}$, a fact that eases considerably the design procedure.

In addition, $T_{a s}$ should be proposed to meet requirements $\mathrm{E}$ and $\mathrm{F}$. Therefore, $T_{a s}=2 s$ is initially proposed, as $T_{a s} / T_{E} \approx 12.5>5$.

Then, $\mathrm{k}_{\text {Dmin }}$ is computed from Eq. 1:

$$
k_{D \min }=\frac{4 \pi^{2} W}{g T_{a s}^{2}}=6.57 \mathrm{Ton} / \mathrm{cm}
$$

Assuming $\kappa=0.11$, the yield shear force and the maximum shear force for the isolation system are: 


$$
\begin{aligned}
& V_{y}=\kappa W=71.83 \text { Ton } \\
& V_{a s}=1.8 V_{y}=129.29 \text { Ton }
\end{aligned}
$$

It is clear from Eq. 5 and (Fig. 1) that the total design displacement $D_{T}$ is:

$$
D_{T}=\frac{V_{a s}}{k_{D \text { min }}}=19.68 \mathrm{~cm}
$$

The total design displacement $D_{T}$ can be estimated in terms of the displacement $D_{D}$ from Eqs. 2 to 4 as:

$$
\begin{aligned}
& D_{2 D}=1.1 D_{D}\left(1.3-0.02 T_{a s}\right)=1.386 D_{D} \\
& D_{T}=1.1 D_{2 D}=1.525 D_{D}
\end{aligned}
$$

Then:

$$
D_{D}=\frac{D_{T}}{1.525}=12.91 \mathrm{~cm}
$$

This displacement capacity $D_{D}$ has to be compared with the demand spectral displacement $S_{d}$, and for an acceptable design, $S_{d} \leq D_{D}$. Given that $T_{a s}=2 s$ and $\zeta_{a s}=\beta_{D}=0.28$, from the displacement design spectra for the site shown in (Fig. 3b), it is obtained that $S_{d}=12.54 \mathrm{~cm}<D_{D}=12.91 \mathrm{~cm}$, then, the global design is acceptable. Therefore, the remaining parameters that define the primary curve for the isolation system are:

$$
\begin{aligned}
& \Delta_{y}=\frac{D_{T}}{9}=2.19 \mathrm{~cm} \\
& k_{1}=5 k_{D \text { min }}=32.848 \text { Ton } / \mathrm{cm} \\
& k_{2}=0.1 k_{1}=3.285 \text { Ton } / \mathrm{cm}
\end{aligned}
$$

A preliminary design for the isolation system is required. This is done with the general procedure outlined in [24], but it is clear that any suitable method can be used for this purpose. Assuming that six LRB will be used as schematically shown in (Fig. 5) $\left(N_{a i s}=6\right)$, and considering that $G_{a i s}=10.2 \mathrm{~kg} / \mathrm{cm}^{2}$ and $\tau_{p b}=107 \mathrm{~kg} / \mathrm{cm}^{2}$, one can approximately determine their dimensions as follows:

$$
\begin{aligned}
& \phi=3 D_{T}=59.04 \mathrm{~cm} \\
& h=\frac{\pi \varphi^{2} G_{a i s}}{4 k_{2} / N_{a i s}}=51.01 \mathrm{~cm} \\
& h / \phi=51.01 / 59.04=0.86>0.8, \text { but close enough } \\
& A_{p b}=\frac{V_{y}-k_{2} \Delta_{y}}{N_{a i s} \tau_{p b}}=100.70 \mathrm{~cm}^{2} \\
& \phi_{p b}=\sqrt{\frac{4 A_{p b}}{\pi}}=11.32 \mathrm{~cm} \\
& \varphi_{p b} / \varphi=11.32 / 59.04=0.19<0.25
\end{aligned}
$$

Therefore, from the preliminary design one can conclude that six LRB with diameter $\phi=60 \mathrm{~cm}$ and height $h=45 \mathrm{~cm}$ can be used, adjusting the diameter of the lead plug $\phi_{p b}$. These required adjustments can be easily done as follows:

$$
h / \phi=45 / 60=0.75<0.8
$$

$$
\begin{aligned}
& D_{T}=\frac{\phi}{3}=20 \mathrm{~cm} \\
& \Delta_{y}=\frac{D_{T}}{9}=2.22 \mathrm{~cm} \\
& k_{2}=\frac{\pi \varphi^{2} G_{a i s}}{4 h / N_{a i s}}=3.845 \mathrm{Ton} / \mathrm{cm} \\
& A_{p b}=\frac{V_{y}-k_{2} \Delta_{y}}{N_{a i s} \tau_{p b}}=98.57 \mathrm{~cm}^{2} \\
& \phi_{p b}=\sqrt{\frac{4 A_{p b}}{\pi}}=11.2 \mathrm{~cm} \\
& \varphi_{p b} / \varphi=11.2 / 60=0.19<0.25
\end{aligned}
$$

These adjustments also modify $k_{2} / k_{1}, k_{D \text { min }}$ and $\beta_{D}$. Given that the adjustment in $h$ is somewhat important, it is reviewed how these adjustments modify the design properties and if the design still satisfies the displacement demand. Therefore:

$$
\begin{aligned}
& k_{1}=\frac{V_{y}}{\Delta_{y}}=\frac{71.83}{2.22}=32.354 \text { Ton } / \mathrm{cm} \\
& k_{2} / k_{1}=3.845 / 32.354=0.119 \\
& V_{a s}=V_{y}+k_{2}\left(D_{T}-\Delta_{y}\right)=140.19 \text { Ton } \\
& k_{D \text { min }}=\frac{V_{a s}}{D_{T}}=7.009 \text { Ton } / \mathrm{cm}
\end{aligned}
$$

Reviewing that the characteristics for the primary curve (Fig. 1) are satisfied (requirement G1):

$$
\begin{aligned}
& \Delta_{2}=0.2 D_{T}=4 \mathrm{~cm} \\
& V_{2}=V_{y}+k_{2}\left(\Delta_{2}-\Delta_{y}\right)=78.67 \text { Ton } \\
& k_{e f f 2}=\frac{V_{2}}{\Delta_{2}}=19.667 \text { Ton } / \mathrm{cm} \\
& k_{D \text { min }} / k_{e f f 2}=0.36>\frac{1}{3}, \text { therefore, o.k. }
\end{aligned}
$$

Then, $\beta_{D}$ for this isolation system is:

$$
\begin{aligned}
& E_{\text {cycle }}=4\left(V_{a s}-k_{2} D_{T}\right)\left(D_{T}-\Delta_{y}\right)=4,500.62 \text { Ton }-\mathrm{cm} \\
& \beta_{D}=\frac{1}{2 \pi}\left[\frac{E_{c y c l e}}{V_{a s} D_{T}}\right]=0.26
\end{aligned}
$$

Then $T_{a s}$ and $D_{D}$ are:

$$
\begin{aligned}
& T_{a s}=2 \pi \sqrt{\frac{W}{g k_{D \text { min }}}}=1.94 \mathrm{~s} \\
& D_{D}=\frac{D_{T}}{1.526}=\frac{20}{1.526}=13.11 \mathrm{~cm}
\end{aligned}
$$

Given that $T_{a s}=1.94 \mathrm{~s}$ and $\zeta_{a s}=\beta_{D}=0.26$, from the displacement design spectra for the site shown in (Fig. 3b), it 
is obtained that $S_{d}=12.38 \mathrm{~cm}<D_{D}=13.11 \mathrm{~cm}$. Therefore, the preliminary design is verified and 6 LRB can be used with the following general characteristics: $\phi=60 \mathrm{~cm}$, $h=45 \mathrm{~cm}$ and $\phi_{p b}=11.2 \mathrm{~cm}$.

It is worth noting that one has still to dimension the thicknesses of the rubber and steel layers of the LRBs, which can be preliminary done with procedures available in the literature [i.e., 22, 23]. Also, a final design necessarily requires an open and close communication with the manufacturer to adjust the characteristics of the isolators, besides many other issues and details of paramount importance in the design and construction of a base-isolation project.

\section{Design of the Structure above the Isolation System}

The minimum design shear force for the structure above the isolation system $V_{E}$ is defined in Eq. 6; therefore, it is required to compute $Q^{\prime}$ as as specified in [5].

$$
\text { As } T_{a s} / T_{E}=1.94 / 0.16=12.13>5,
$$

then $Q_{a s}^{\prime}=R_{a s} \rho_{a s} \geq 1$. Given that the structure above the isolation system is composed of confined masonry shear walls made with solid units, then the overstrength index factor is $R_{a 0}=1.6$. As $T_{E}=0.16 \mathrm{~s}<T_{a}=0.175 \mathrm{~s}$, then, the overstrength factor $R_{a s}$ is:

$$
R_{a s}=R_{a 0}+0.3\left(1-\sqrt{\frac{T_{E}}{T_{a}}}\right)=1.61
$$

It can be observed from Fig. (5) that the redundancy factor $\rho_{a s}$ (explained in [5]) is ruled by the isolation system. Therefore, from (Fig. 5), $\rho_{a s}=0.8$ should be taken in the Y direction as the isolation system is forming an equivalent "three parallel one-bay frames system", whereas in the X direction, $\rho_{a s}=1$ because the isolation system is forming an equivalent "two parallel two-bay frames system". Therefore, as $\rho_{a s}$ is different in both orthogonal directions, then:

$$
\begin{aligned}
& Q_{a s_{x}}^{\prime}=1.61(1)=1.61 \\
& V_{E_{x}}=\frac{V_{a s}}{Q_{a s_{x}}^{\prime}}=\frac{140.19}{1.61}=87.1 \text { Ton } \\
& Q_{a s_{y}}^{\prime}=1.61(0.8)=1.29 \\
& V_{E y}=\frac{140.19}{1.29}=108.8 \text { Ton }
\end{aligned}
$$

It is worth noting again that the values of $V_{E}$ shall not be taken as less than: (1) the lateral seismic force required for a fixed-base structure $\left(V_{E f b}\right)$ of the same effective weight, $W$, and a period equal to the isolated period, $T_{a s}$ or, (2) the base shear corresponding to the factored design wind load $\left(V_{E w}\right)$. The computation $V_{E f b}$ and $V_{E w}$ according to MOC-2012 requires of additional information and explanations that are not yet available in English language, particularly for the wind design. Therefore, $V_{E w}$ was not assessed as it is not germane to illustrate the method.

On the other hand, $V_{E f b}$ was assessed according to the seismic guidelines for conventional buildings of MOC-2008 $[1,2]$. Because of space constraints, and in the interest of the understanding of the simplified method, this calculation will be briefly described as follows. With $T_{a s}=1.94 \mathrm{~s}$ and $\varsigma=0.05$, it is obtained from the acceleration design spectra shown in (Fig. 3a) that $S_{a}=0.278 \mathrm{~g}$. As $a^{\prime}=S_{a} / Q^{\prime} R \rho$ then, it is required to define the overstrength factor $R$, the redundancy factor $\rho$ and $Q^{`}$ factor for the structural system shown in (Fig. 4). From the analysis of Fig. (4), it is obtained that $\rho=1$ in both orthogonal directions. As $T_{a s}=1.94 s>T_{a}=0.175 \mathrm{~s}$, then $R=R_{0}=2.5$ for confined masonry shear wall structures. The computation of $Q^{\prime}$ is

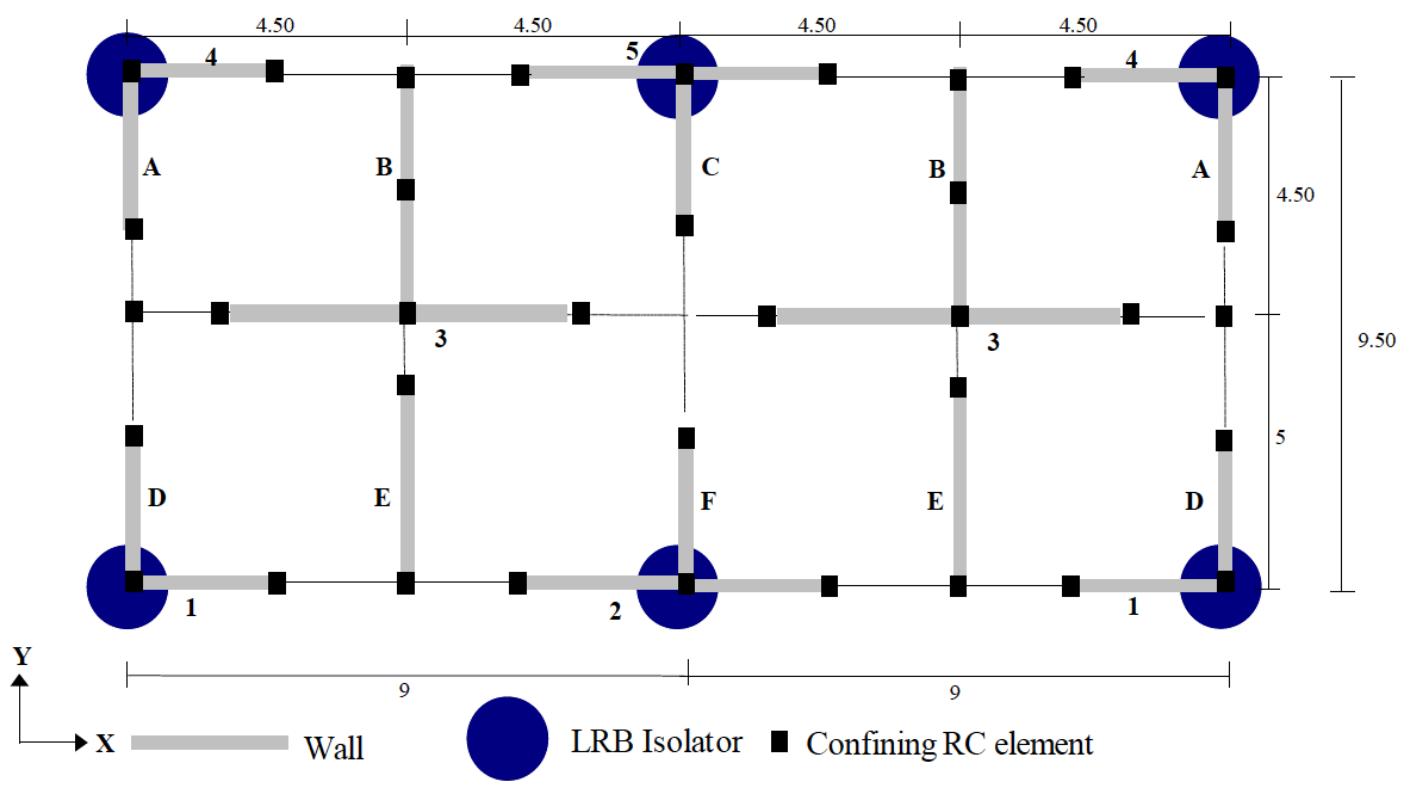

Fig. (5). Schematic location of LRB for the isolation project (dimensions in meters). 
more complex, so following the guidelines described in [2], it is obtained that $Q^{\prime}=1.80$. Then:

$$
\begin{aligned}
& a^{\prime}=\frac{0.278 g}{1.80(2.5)(1)}=\frac{0.278 g}{4.50}=0.062 \mathrm{~g} \\
& V_{E f b}=1.1 a^{\prime} \mathrm{W}=44.4 \mathrm{Ton}
\end{aligned}
$$

Therefore, it is clear that $V_{E_{x}}>V_{E f b}$ and $V_{E_{v}}>V_{E f b}$, so $V_{E_{x}}$ and $V_{E_{y}}$ should be used for the design of the structure above the isolation system.

The vertical distribution of lateral forces in the superstructure is given by Eq. 7. Therefore, from the information provided in this example, and considering that for seismic analysis, the masses (weights) of walls within an interstory are distributed in halves between the corresponding adjacent stories, it is obtained that:

$$
\begin{aligned}
& F_{4 x}=87.1 \frac{113.09}{530}=18.59 \mathrm{Ton} ; \\
& F_{1 x}=F_{2 x}=F_{3 x}=87.1 \frac{138.97}{530}=22.84 \mathrm{Ton} \\
& F_{4 y}=108.8 \frac{113.09}{530}=23.22 \mathrm{Ton} ; \\
& F_{1 y}=F_{2 y}=F_{3 y}=108.8 \frac{138.97}{530}=28.53 \mathrm{Ton}
\end{aligned}
$$

The predesign of the walls using the SMSA requires first to assess the compressive strength required for the masonry $\left(f^{*}{ }_{m}\right)$ and the solid clay bricks $\left(f^{*}{ }_{p}\right)$ to withstand the vertical load combinations according to Mexican masonry guidelines [19]. It is beyond the scope of this paper to illustrate this simple procedure, which is described in detail in [25]. Summarizing the design for gravitational loads, the critical element is wall $\mathrm{F}$ at the first story (Fig. 3), and accordingly, it is required for the masonry to have a minimum design compressive strength $f_{m}^{*}=22.75 \mathrm{~kg} / \mathrm{cm}^{2}$, and since mortar type I is used, therefore, the fired clay bricks should possess a compressive strength $f_{p}^{*}=65 \mathrm{~kg} / \mathrm{cm}^{2}$. With such properties for the bricks and as mortar type I is used, the index shear strength for design for the masonry is $v_{m} *=3.5 \mathrm{~kg} / \mathrm{cm}^{2}$.

The seismic design for the shear walls using the SMSA will be illustrated for the walls of the first story in the critical $\mathrm{Y}$ direction, where $V_{E_{y}}=108.8$ Ton. From the information given in the definition of the example, the plan shown in (Fig. 4) and Equation 9, it is obtained that, in the $\mathrm{Y}$ direction:

$$
\begin{aligned}
& A_{y}=\sum A_{T i} F_{A E_{i}}=6(0.375)(1.185)+ \\
& 2(0.563)(1.56)+2(0.5)(1.4916)=5.91 \mathrm{~m}^{2}
\end{aligned}
$$

The shear forces that each wall type have to resist in the $\mathrm{Y}$ direction $\left(V_{j i_{v}}\right)$ are computed from Eq. 8 taking $V_{i}=V_{1 y}=V_{E_{y}}=108.8 \mathrm{Ton}$. These computed shear forces $V_{j i_{y}}$ are compared in Table 2 with the estimated shear strength capacity for each wall according to Mexican masonry guidelines, $V_{m R}[$ i.e., 19, 26]. Details on the assessment of $V_{m R}$ for each wall considering that horizontal shear reinforcement is not provided and are presented in [25].
From the observation of the data presented in Table 2, it can be concluded that only wall $\mathrm{B}$ does not have enough shear strength capacity without horizontal shear reinforcement. However, the SMSA also allows to do a gross strength evaluation where $\sum V_{m R} \geq V_{E_{v}}$ and, from the data given in (Table 2 and Fig. 3), it is obtained that $\sum V_{m R_{y}}=114.5$ Ton $>V_{E_{y}}$, so the design is tight, but acceptable. In addition, the design for the walls in the $\mathrm{Y}$ direction can be easily improved providing the minimum horizontal shear reinforcement as established by the Mexican masonry guidelines [i.e., 19, 26]. It is beyond the scope of this paper to present such refinement.

As reported [25], all walls in the $\mathrm{X}$ direction have enough shear strength capacity to resist the earthquake demands without horizontal shear reinforcement and for this direction, the gross evaluation yields $\sum V_{m R_{x}}=108.8 T o n>V_{E x}=87.1 T o n$.

This example illustrates that the simplified method for the seismic design of low-rise, shear wall base-isolated structures prescribed in MOC-2008 is easy to apply. Most of the required calculations can be easily programmed or implemented in spreadsheet software (for example: http://www.researchgate.net/profile/Arturo_TenaColunga/contributions/?ev=prf_act).

\section{REVIEW USING NONLINEAR DYNAMIC ANALYSIS}

The effectiveness of the design obtained using the simplified method is assessed with nonlinear time-history analyses done according to the same MOC-2012 guidelines [1,2].

For this purpose, 16 pairs of orthogonal horizontal ground motion components corresponding to eight different earthquakes events $M>6.4$ recorded in firm soils in Mexico were selected, as identified in Tables $\mathbf{3}$ and $\mathbf{4}$. The selected records were individually scaled in order that the dominant ground component will match the spectral acceleration $S_{a}=0.274 \mathrm{~g}$ for $T_{a s}=2 \mathrm{~s}$ for the design spectrum for $\zeta=0.05$ shown in (Fig. 3a). The same factor was used to scale the two orthogonal components (E-W and N-S), for each pair of acceleration records under study. These records were corrected, filtered and processed similarly as reported in a previous study [17], as they belong to the same database.

Nonlinear time-history analyses were conducted using the 3D-Basis software [27]. Bidirectional input of the scaled ground motions was considered, switching components in order to crudely consider directivity effects. LRB were modeled individually using the hysteretic element with biaxial behavior available in $3 \mathrm{D}$-Basis. The structure above the isolation system was modeled as a 3D shear building. In fact, this is the modeling assumption behind the SMSA allowed by Mexican codes for low-rise shear wall buildings [i.e., 10, 11]. Twelve modes were considered in the 3D-Basis analyses. It is worth noting that the translational fixed-base periods computed with 3D-Basis under this modeling assumption were $T_{E_{X}}=0.187 \mathrm{~s}$ and $T_{E_{v}}=0.175 \mathrm{~s}$, reasonably close to the natural period estimated for preliminary design purposes $\left(T_{E} \approx 0.04 N=0.16 s\right)$.

Peak dynamic responses obtained from the nonlinear dynamic analyses are summarized in Table $\mathbf{3}$ (structure above the isolation system) and Table 4 (isolation system). It is 
Table 2. Review of the shear capacity of the first story walls in the Y direction (Fig. 3 ).

\begin{tabular}{|c|c|c|c|c|}
\hline Wall Type & $\mathbf{A}_{\mathrm{Ti}} / \mathbf{A}_{\mathbf{y}}$ & $V_{j i y_{y}}$ (Ton) & $V_{m R}$ (Ton) & Note \\
\hline $\mathbf{A}$ & 0.0752 & 8.18 & 8.46 & $\checkmark$ \\
\hline C & 0.0752 & 8.18 & 10.93 & $\checkmark$ \\
\hline D & 0.0752 & 8.18 & 9.04 & $\checkmark$ \\
\hline F & 0.0752 & 8.18 & 12.09 & $\checkmark$ \\
\hline
\end{tabular}

Table 3. Peak dynamic responses for the superstructure of the base-isolated masonry building under bidirectional input of the ground motions.

\begin{tabular}{|c|c|c|c|c|c|c|c|c|c|}
\hline Station & Quake & \multicolumn{2}{|c|}{ Peak roof displacement $(\mathrm{mm})$} & \multicolumn{2}{|c|}{ Peak drift angle } & \multicolumn{2}{|c|}{ Peak roof acceleration (g) } & \multicolumn{2}{|c|}{ Normalized peak base shear } \\
\hline AZIH & $85 / 09 / 19$ & 1.23 & 1.65 & 0.00019 & 0.00026 & 0.134 & 0.157 & 0.108 & 0.127 \\
\hline CALE & $85 / 09 / 19$ & 1.19 & 0.97 & 0.00018 & 0.00015 & 0.130 & 0.095 & 0.105 & 0.075 \\
\hline PAPN & $85 / 09 / 19$ & 1.03 & 2.02 & 0.00016 & 0.00031 & 0.113 & 0.195 & 0.090 & 0.155 \\
\hline UNIO & $85 / 09 / 19$ & 1.09 & 1.69 & 0.00016 & 0.00026 & 0.122 & 0.162 & 0.094 & 0.130 \\
\hline VILE & $85 / 09 / 19$ & 1.52 & 1.33 & 0.00023 & 0.00021 & 0.165 & 0.129 & 0.134 & 0.103 \\
\hline AZIH & $85 / 09 / 20$ & 1.70 & 1.43 & 0.00026 & 0.00022 & 0.184 & 0.138 & 0.149 & 0.109 \\
\hline COPL & $95 / 09 / 14$ & 1.08 & 1.92 & 0.00017 & 0.00030 & 0.120 & 0.184 & 0.095 & 0.148 \\
\hline UNIO & $97 / 01 / 11$ & 1.14 & 1.87 & 0.00017 & 0.00029 & 0.126 & 0.182 & 0.099 & 0.144 \\
\hline CUER & $99 / 06 / 15$ & 1.45 & 1.45 & 0.00022 & 0.00022 & 0.158 & 0.139 & 0.127 & 0.111 \\
\hline CSER & $99 / 09 / 30$ & 1.23 & 1.60 & 0.00019 & 0.00025 & 0.134 & 0.154 & 0.108 & 0.124 \\
\hline CUER & $99 / 09 / 30$ & 1.07 & 1.28 & 0.00016 & 0.00020 & 0.116 & 0.123 & 0.094 & 0.099 \\
\hline PPIG & $99 / 09 / 30$ & 1.02 & 1.29 & 0.00016 & 0.00020 & 0.111 & 0.123 & 0.090 & 0.100 \\
\hline$\sigma$ & & 1.27 & 1.51 & 0.00019 & 0.00023 & 0.139 & 0.146 & 0.111 & 0.116 \\
\hline
\end{tabular}

worth noting that, according to the time-history procedure defined in MOC-2012 [4], if seven or more pairs of timehistory analyses are performed, the average value of the response parameter of interest shall be used for design, which is why the mean value $(\mu)$ is also provided in these tables.

It can be deducted from the results presented in Table 3 that the isolation of the superstructure is effective. The superstructure practically responses as a rigid body with negligible peak roof displacements with respect to the isolation level and peak drift angles (at first story) considerable below the limit $\Delta=0.0015$ allowed by MOC-2012 for base-isolated structures with confined masonry walls built with solid units $[4,5]$.
The peak acceleration profile is also fairly uniform, as the structure displaces almost as a rigid body. The average amplification factor between the peak acceleration at the first story (not shown) and the peak roof acceleration (Table $\mathbf{3}$ ) is 1.03. Therefore, these results illustrate the rationality behind the uniform lateral force distribution for the superstructure proposed in Eq. 7. Finally, normalized shear strength capacities for the confined masonry structure are $\sum V_{m R_{.}} / W=0.167$ and $\sum V_{m R_{v}} / W=0.175$, higher than the average and maximum normalized peak base shear demands $V_{x e} / W$ and $V_{y e} / W$ reported in Table 3 .

It can be confirmed from the results presented in Table $\mathbf{4}$ that the base-isolation project is effective, as the reported 
Table 4. Peak dynamic responses for the isolation system of the base-isolated masonry building under bidirectional input of the ground motions.

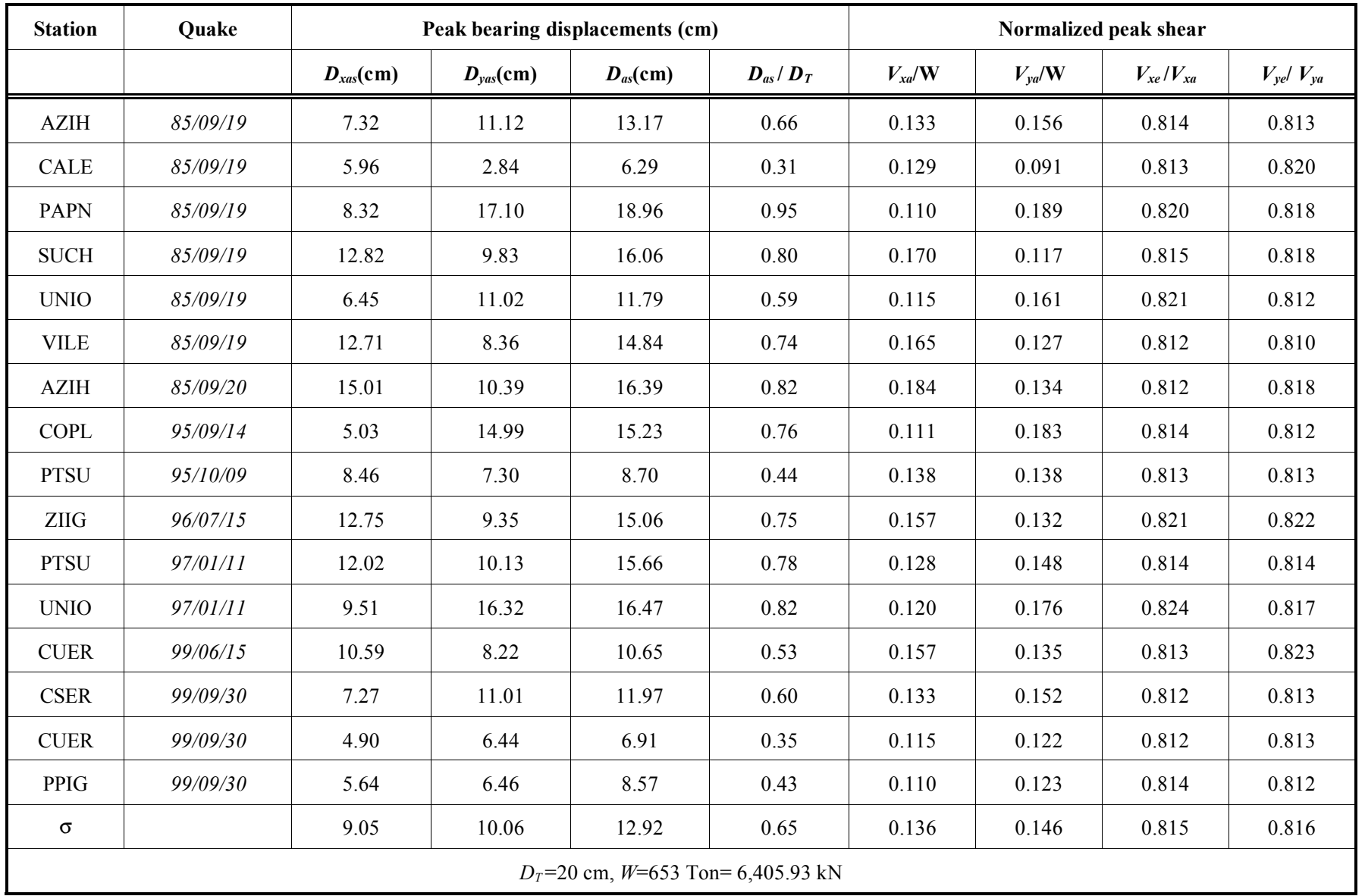

peak LRB displacement demands $D_{a s}$ are smaller than the total design displacement $D_{T}$. In addition, the normalized shear strength capacity for the isolation system is $V_{a s} / W=0.215$, higher than the average and maximum normalized peak shear demands for the isolation system $V_{x a} / W$ and $V_{y a} / W$ reported in Table 4. Finally, a fairly constant reduction in the shear force transmitted to the superstructure $(81.5 \%)$ is also observed.

\section{CONCLUDING REMARKS}

A simplified method for the seismic design of low-rise, base-isolated shear wall structures proposed in the model code MOC-2012 of Mexico was presented. The spirit behind this simple method is to help promote the application of base-isolation in regular and squatty shear wall structures in Mexico by facilitating their seismic design process.

A simple design example was presented to help illustrate the application of the method. The effectiveness of the method in leading to safe structural designs was confirmed with nonlinear time-history analyses (NTHA) done according to the same MOC-2012 guidelines. It was verified with NTHA that: a) the superstructure practically responses as a rigid body with negligible peak roof displacements with respect to the isolation level, b) peak drift angles at the superstructure are considerable below the limit $\Delta=0.0015$ allowed by MOC2012 for base-isolated structures with confined masonry walls built with solid units, c) the peak acceleration profile for the superstructure is fairly uniform, as the structure displaces almost as a rigid body. The assessed average amplification factor between the peak acceleration at the first story and the peak roof acceleration is 1.03 only, $d$ ) the normalized shear strength capacities for the confined masonry are higher than the average and maximum normalized peak base shear demands, e) peak LRB displacement demands are smaller than the total design displacement the isolators can accommodate and, f) the normalized shear strength capacity for the isolation system is higher than the average and maximum normalized peak shear demands for the isolation system. Therefore, it can be concluded that this simplified method seems to be a promising tool to achieve safe designs for lowrise base-isolated shear wall structures in a practical way.

\section{CONFLICT OF INTEREST}

The author(s) confirm that this article content has no conflicts of interest.

\section{ACKNOWLEDGEMENT}

The financial support of Comisión Federal de Electricidad (CFE) through a research grant to Instituto de Ingeniería, UNAM, and the Fulbright-García Robles program for researchers, are gratefully acknowledged. 


\section{REFERENCES}

[1] MOC-2008, Manual de Diseño de Obras Civiles. Diseño por Sismo, México: Comisión Federal de Electricidad, 2009. (in Spanish)

[2] A. Tena-Colunga, U. Mena-Hernández, L. E. Pérez-Rocha, J. Avilés, M. Ordaz and J. I. Vilar, "Updated Seismic Design Guidelines for Buildings of a Model Code of Mexico", Earthquake Spectra, vol. 25 , no. 4 , pp. 869-898, 2009.

[3] A. Tena-Colunga, "International Seismic Zone Tabulation Proposed by the 1997 UBC Code: Observations for Mexico", Earthquake Spectra, vol. 15, no. 2, pp. 331-360, 1999.

[4] MOC-2012, Manual de Diseño de Obras Civiles. Tema 3, Capítulo 2. Diseño de Estructuras con Aislamiento de Base. Recomendaciones y Comentarios, México: Comisión Federal de Electricidad, 2012. (in Spanish)

[5] A. Tena-Colunga, "Seismic Design of Base-Isolated Buildings in Mexico. Part 1: Guidelines of a Model Code", The Open Civil Engineering Journal, vol. 7, pp. 17-31, 2013.

[6] UBC-97, Uniform Building Code, 1997 ed, Whittier, California: International Conference of Building Officials, 1997.

[7] ASCE-7, Minimum Design Loads for Buildings and Other Structures, ASCE Standard ASCE/SEI 7-10, Reston, Virginia: American Society of Civil Engineers, 2010.

[8] IBC-12, International Building Code, 2012 ed, Country Club Hills, Illinois: International Code Council, 2012.

[9] FEMA-450, NEHRP Recommended Provisions for Seismic Regulations for New Buildings and Other Structures. Part 1: Provisions, FEMA Publication 450, Washington, DC: Federal Emergency Management Agency, 2004.

[10] A. Tena-Colunga and J. Cano-Licona, "Simplified Method for the Seismic Analysis of Masonry Shear-Wall Buildings", ASCE Journal of Structural Engineering, vol. 136, no. 5, pp. 511-520, 2010.

[11] A. Tena-Colunga and A. López-Blancas, "Allowable torsional eccentricity for the simplified method for the seismic analysis of confined masonry shear-wall buildings," The Open Civil Engineering Journal, vol. 5, pp. 132-142, 2011.

[12] D. M. Lee, "Base isolation for torsion reduction in asymmetric structures under earthquake loading", Earthquake Engineering and Structural Dynamics, vol. 8, pp. 349-359, 1980.

[13] M. Eisenberger and A. Rutenberg, "Seismic base isolation of asymmetric shear buildings", Engineering Structures, vol. 8, no. 1, pp. 2-9, 1986

[14] S. Nagarajaiah, A. M. Reinhorn and M. C. Constantinou, "Torsion in base isolated structures with elastomeric isolation systems", ASCE Journal of Structural Engineering, vol. 119, no. 10, pp. 2932-2951, 1993.
[15] A. Tena-Colunga and C. Zambrana-Rojas, "Dynamic torsional amplifications of base-isolated structures with an eccentric isolation system", Engineering Structures, vol. 28, no. 1, pp. 72-83, 2006.

[16] F. Mazza, A. Vulcano and M. Mazza, "Nonlinear dynamic response of rc buildings with different base isolation systems subjected to horizontal and vertical components of near-fault ground motions", The Open Construction and Building Technology Journal, vol. 6, pp. 373-383, 2012.

[17] A. Tena-Colunga and M. A. Pérez-Osornio, "Design displacements for base isolators considering bidirectional seismic effects", Earthquake Spectra, vol. 22, no. 3, pp. 803-825, 2006.

[18] C. E. Seguín, "Torsión en Sistemas Aislados Sísmicamente con Dispositivos Elastoméricos", Ph.D. Thesis, Escuela de Ingeniería, Pontificia Universidad Católica de Chile, Santiago, Chile, December, 2007. (in Spanish)

[19] NTCM-2004, Normas Técnicas Complementarias para Diseño y Construcción de Estructuras de Mampostería, México DF: Gaceta Oficial del Distrito Federal, October, 2004 (in Spanish).

[20] A. Tena-Colunga and M. A. Pérez-Osornio, "Assessment of shear deformations on the seismic response of asymmetric shear wall buildings", ASCE Journal of Structural Engineering, vol. 131, no. 11, pp. 1774-1779, 2005 .

[21] D. Murià and R. González, "Propiedades Dinámicas de Edificios de la Ciudad de México," Revista de Ingeniería Sísmica, no. 51, pp. 25-45, 1995. (in Spanish)

[22] R. I. Skinner, W. H. Robinson and G. H. Mc Verry, An Introduction to Seismic Isolation, England: John Wiley and Sons, 1993.

[23] F. Naeim and J. M. Kelly, Design of Seismic Isolated Structures, New York: John Wiley \& Sons, 1999.

[24] A. Tena-Colunga, "Seismic design of base-isolated structures using capacity spectra", Journal of Earthquake Engineering, vol. 6, no. 4, pp. 553-586, 2002

[25] MOC-2012b, Manual de Diseño de Obras Civiles. Tema 3 , Capítulo 2, Diseño de Estructuras con Aislamiento de Base. Ayudas de Diseño, México: Comisión Federal de Electricidad, 2012. (in Spanish)

[26] S. M. Alcocer, J. Cesín, L. E. Flores, O. Hernández, R. Meli, A. Tena-Colunga and D. Vasconcelos, "The New Mexico City Building Code Requirements for Design and Construction of Masonry Structures", in Proceedings of Ninth North American Masonry Conference, Clemson, South Carolina, 2003, pp. 656-667.

[27] S. Nagarajaiah, A. M. Reinhorn and M. C. Constantinou, "3DBasis: Nonlinear Dynamic Analysis of Three-Dimensional Base Isolated Structures: Part II", Technical Report NCEER-91-0005, National Center for Earthquake Engineering, State University of New York at Buffalo, 1991.

(C) Arturo Tena-Colunga; Licensee Bentham Open.

This is an open access article licensed under the terms of the Creative Commons Attribution Non-Commercial License (http://creativecommons.org/licenses/by-nc/3.0/) which permits unrestricted, non-commercial use, distribution and reproduction in any medium, provided the work is properly cited. 